\title{
Human Papiloma Virus Detection in Various Cervical Lesions by Molecular Methods
}

\section{A R T I C L E I N F O}

\section{Article Type}

Original research

\section{Authors}

Hasani M.* MSC

Salehian P. ${ }^{1} M D$

Pourazar Sh. ${ }^{2} M S c$

\section{How to cite this article}

Hasani M, Salehian P, Pourazar Sh.

Human Papiloma Virus Detection

in Various Cervical Lesions by

Molecular Methods. Sarem Jou-

rnal of Reproductive Medicine.

2017;1(3):113-116.
*Sarem Cell Research Center (SCRC), Sarem Women's Hospital, Tehran, Iran

${ }^{1}$ Sarem Cell Research Center (SCRC), Sarem Women's Hospital, Tehran, Iran

${ }^{2}$ Masoud's Pathobiology Lab, Tehran, Iran

\section{Correspondence}

Address: Sarem Women's Hospital, Basij Square, Phase 3, Ekbatan Town, Tehran, Iran. Postal Code: 1396956111

Phone: +98 (21) 44670888

Fax: +98 (21) 44670432

mha1353@gmail.com

\section{Article History}

Received: March 15, 2016

Accepted: January 14,2016

ePublished: August 15, 2017

\section{A B S T R A C T}

Aims Human Papilloma Virus (HPV) is known as one of the causes of anogenital cancers, including cervix cancer. The inability of viral culture has made the initial detection of HPV difficult. Therefore, molecular methods are the best way to identify, and among these methods, Polymerase Chain Reaction (PCR) amplification methods are very useful and accurate in diagnosis. The aim of this study was to investigate the presence of HPV in Iranian patients and the relationship between the type of virus (high risk and low risk) and cervical lesions by molecular methods based on PCR virus samples.

Materials \& Methods The present study was conducted on 67 biopsy and Liquid base cytological samples including cervical Liquid cytology and cervical tissue biopsy. The cytological diagnostic test and pathological examination were performed and the DNA was extracted and then, DNA typing was conducted by PCR using primers MY09/MY11, specific for capsid gene. Findings Out of 67 patients, 2 cases (3.0\%) were not infected with HPV, while cervical cytology was symptomatic. Seven cases had no symptoms in the cervical epithelial cells, which were virtually positive for the virus, and the rest also had both viral and clinical symptoms. Most of the samples (52.2\%) were infected with high-risk viruses and, most of them were HPV16.

Conclusion HPV can be the main responsible for the cervical cells changes, that has the ability to become cancerous. Also, in most cases, the main cause of the infection is high-risk type of the virus. The most prevalent type of HPV that infected cervical epithelial cells is HPV16.

Keywords Human Papilloma Virus; Uterine Cervical Erosion; Molecular Diagnostic Technique

\section{I T A T I O N L I N KS}

[1] Treatment of Condyloma acuminatum with krayotherapy [2] HPV DNA testing: Technical and programmatic issues for cervical cancer prevention in low-resource settings [3] Definitions \& Characteristics of HPV: Merck Medicos Modules [4] Andrews' Diseases of the Skin [5] Detection of human papillomavirus deoxyribonucleic acid in the female genital tract [6] Study of human papilloma virus in anogenital condylomas by PCR method [7] Cervical intraepithelial neoplasia 3, coinfected with HPV-16 and -18 -case report [8] Methods for HPV detection: Polymerase chain reaction assays [9] Viral infections [10] Comparison of three management strategies for patients with atypical squamous cells of undetermined significance: Baseline results from a randomized trial [11] Comparison of the hybrid capture tube test and PCR for detection of human papillomavirus DNA in cervical specimens [12] Utilization of human papillomavirus testing for cervical cancer prevention in a university hospital 


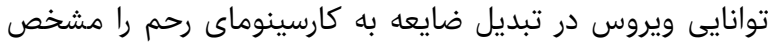

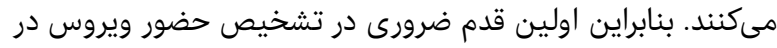

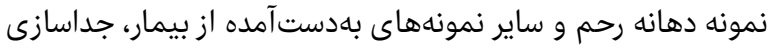

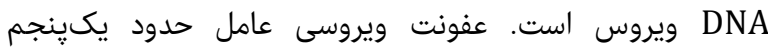

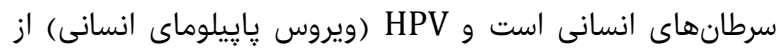

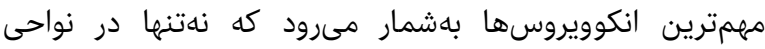

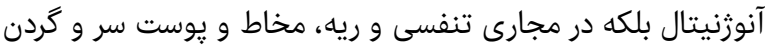

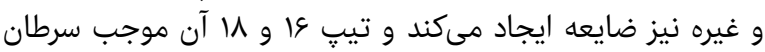

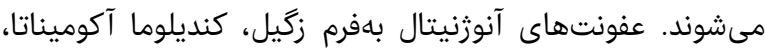

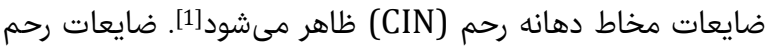

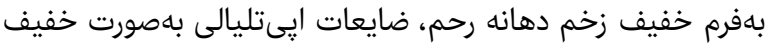

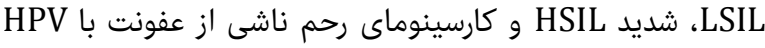
مىتوانند وجود داشته باشند[3]

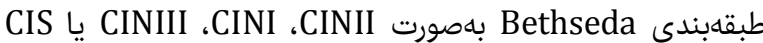

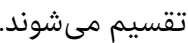

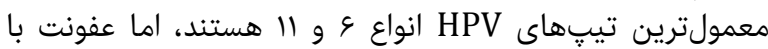

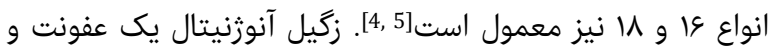

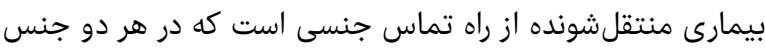

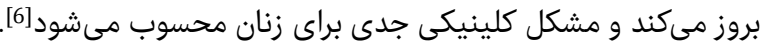

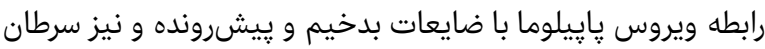

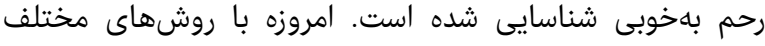
مانند تكثير DNA هدف با PCR و روش

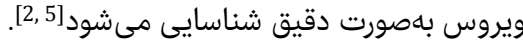

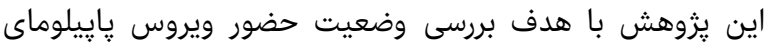

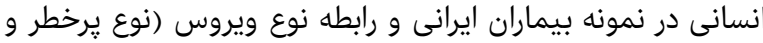

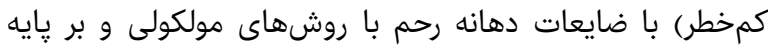
PCR

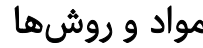

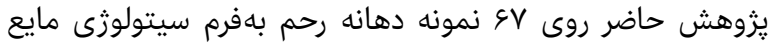

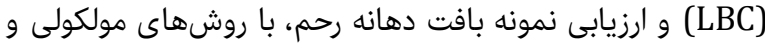
بر يايه PCR در بيمارستان صارم صورت كرفت ديان.

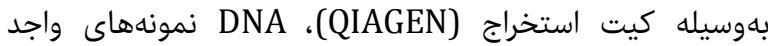
ضايعات دهانه رحم، كنديلوما و سرطان رحم استخراج شد. براى لراي تعيين حضور HPV در نمونه بيمار از يرايمر

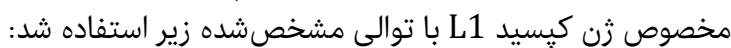

Forward: 5'-CGTCCMANNGGASACTGATC-3' Reverse: 5'-GCMCAGGGSCATAKAATG-3' $\mathrm{C} / \mathrm{A}=\mathrm{M} \mathrm{G} / \mathrm{A}=\mathrm{N} \mathrm{T} / \mathrm{A}=\mathrm{S} \mathrm{T} / \mathrm{C}=\mathrm{K}$

با كمك ترايمر اختصاصى L1 كيسيدى ويروس و با رعايت دماهاى مراحل مختلف PCR در دستكاه ترايمر ترموسايكلر، دماى باى

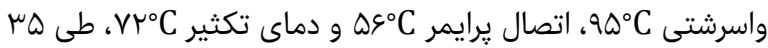

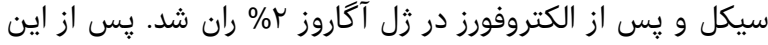

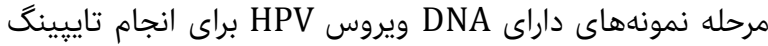

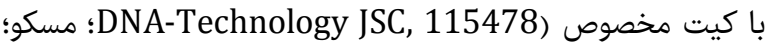

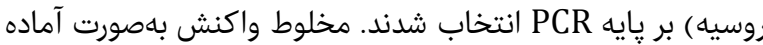

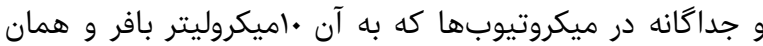

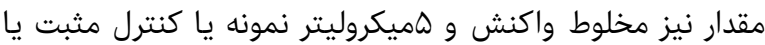

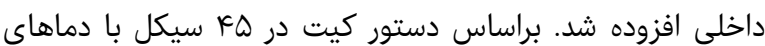
واسرشتى
بررسى حضور يايِيلوما ويروس انسانى در انواع

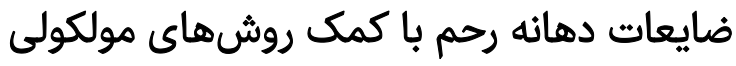

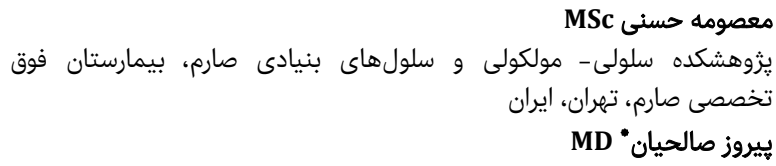

يزوهشكده سلولى- مولكولى و سلولهان مانى بنيادى صارم، بيمارستان فوق تخصصى صارم، تهران، ايران

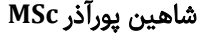

آزمايشگاه پِاتوبيولوزى مسعود، تهران، ايران

جكيده

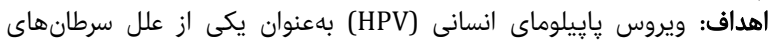

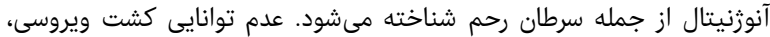

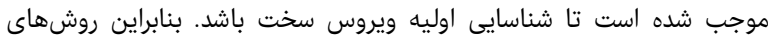

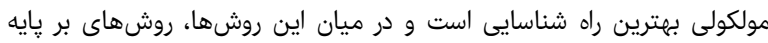

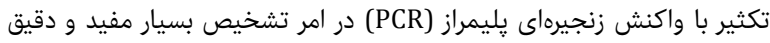

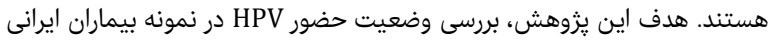

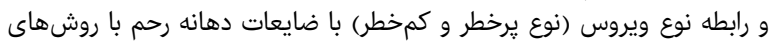

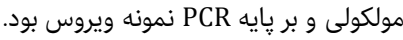

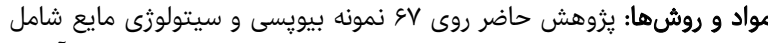

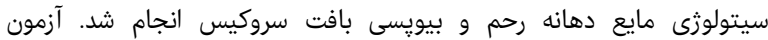

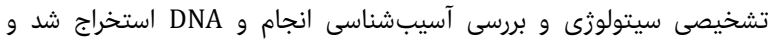

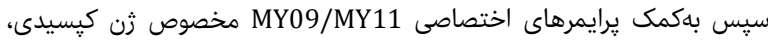

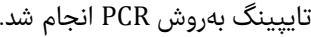

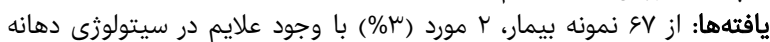

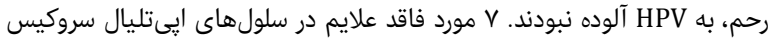

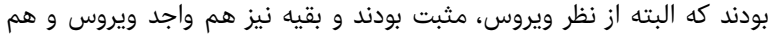

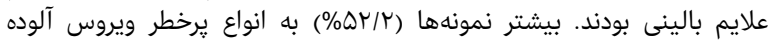

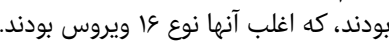

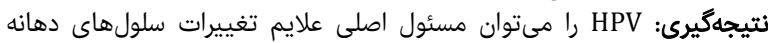

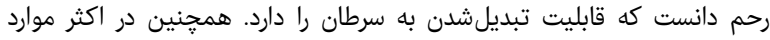

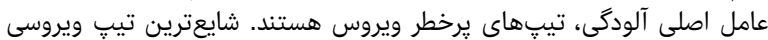

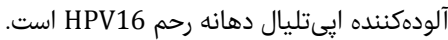

كليدوازمها: ويروس يإييلوهاى انسانى، ضايعات دهانه رحم، آزمون تشخيص مولكولى إنى

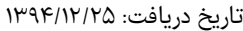

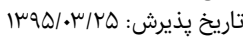

نويسنده مسئول: mha1353@gmail.com

مقدمه

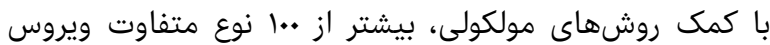

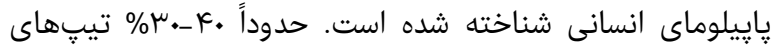

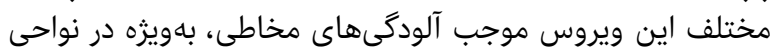

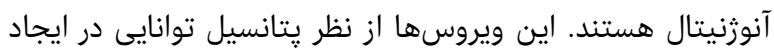

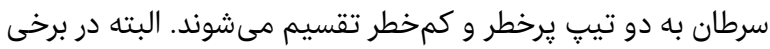

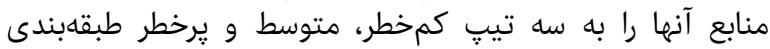

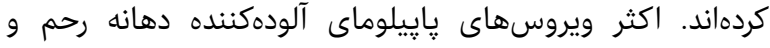

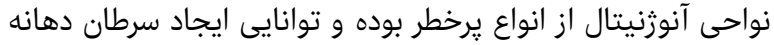

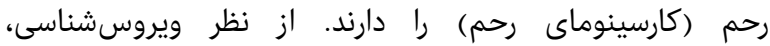

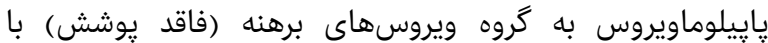

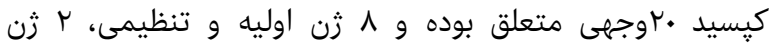

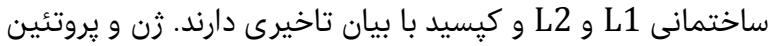

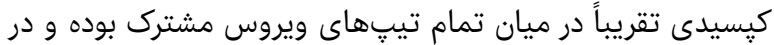

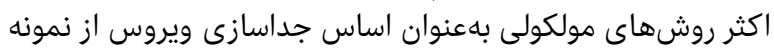
بيمار قرار مىگيرند. از بين ^^ ثن بن تنظيمى، زنهاى 
بررسى حضور ياييلوما ويروس انسانى در انواع ضايعات دهانه رحم با كمك روشهاى مولكولى 110

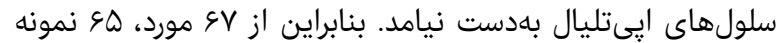

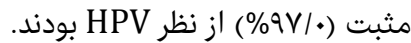

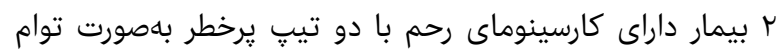

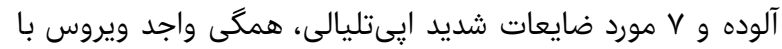

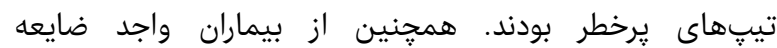

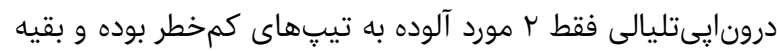

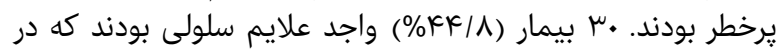

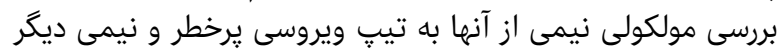

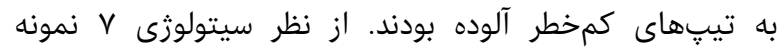

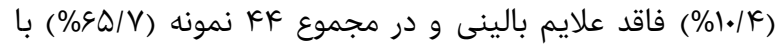
ويروس تيڤهاى يرخطر آلوده بودند (جدول إ نمودار () ).

جدول 1) فراوانى مطلق و نسبى (اعداد داخل يرانتز درصد هستند) ضايعات

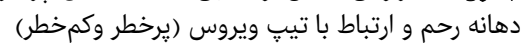

\begin{tabular}{|c|c|c|c|c|}
\hline مجموع & $\begin{array}{l}\text { HPV } \\
\text { (neg) }\end{array}$ & $\begin{array}{c}\text { Low-Risk } \\
\text { HPV }\end{array}$ & $\begin{array}{c}\text { High-Risk } \\
\text { HPV }\end{array}$ & ضايعات \\
\hline$(\mu / \cdot)^{r}$ & $\cdot$ & $\cdot$ & $(\mu / \cdot) r$ & Carcinoma of Cervix \\
\hline$(9 / \cdot)^{8}$ & • & • & $(9 / \cdot)^{9}$ & CINIII \\
\hline$(1 \cdot / F) V$ & • & • & $(1 . / F) V$ & CINII \\
\hline$(K r / K) 10$ & $(\mu / \cdot) r$ & $(\mu / \cdot) r$ & $(\mid \varepsilon / k) \|$ & CINI \\
\hline$(K F / \Lambda) \mu$. & • & $(Y \mu / K) 10$ & $(K+/ K) 10$ & HPV Cytopathic Effect \\
\hline$(1 . / F) V$ & • & $(\varepsilon / \cdot)^{k}$ & $(K / F)^{\mu}$ & Without Sign \\
\hline$(1 . .1 \cdot) \& V$ & $(\mu / \cdot)^{r}$ & 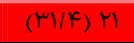 & $(\xi \Delta / 8) K F$ & 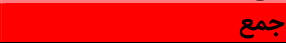 \\
\hline
\end{tabular}

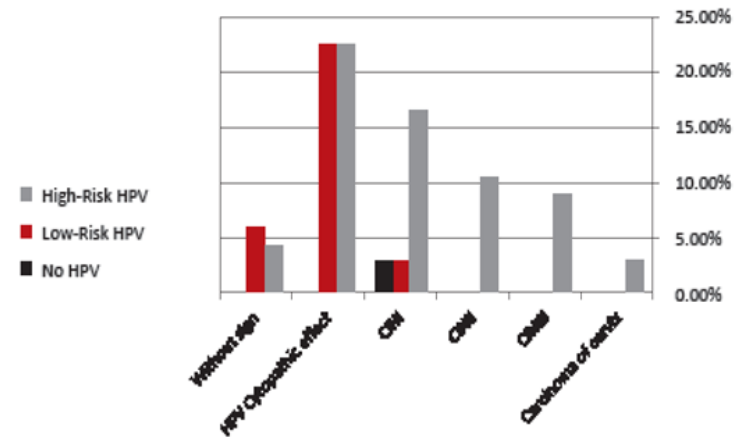

نمودار 1) ارتباط ضايعات دهانه رحم با تيیهاى ويروس يرخطر و كمخطر

بيشترين موارد آلودگى مربوط به تيب 18 ويروس بود. در ميان

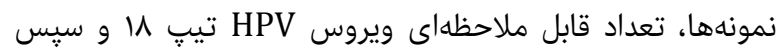

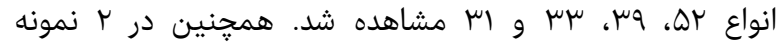

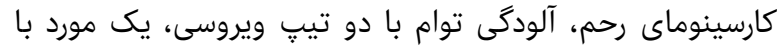

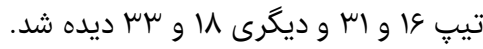

بحث

يُزوهش حاضر با هدف بررسى وضعيت حضور ويروس بإِيلوماى

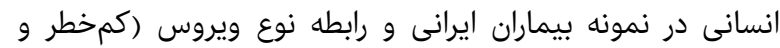

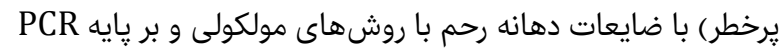

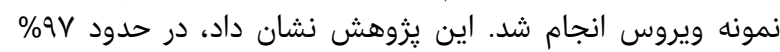

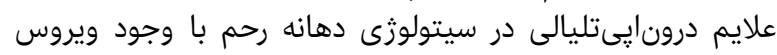

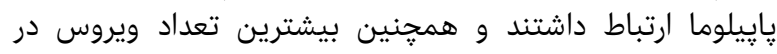

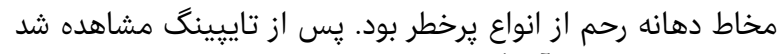

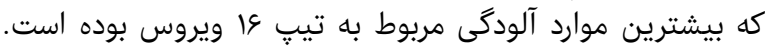

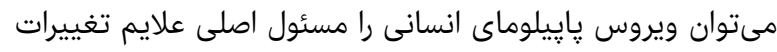
سلولهاى دهانه رحم دانست كه بالقوه قابليت ايجاد سرطان رانئ را دارد

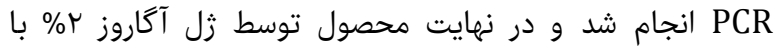

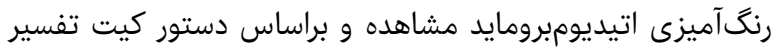

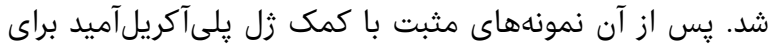
نوع او برخى بكروش PCR در زمان واقعى (Real time PCR)

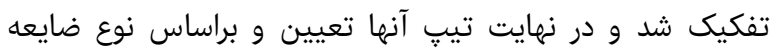

طبقهبندى شدند.

يافتهها

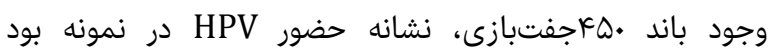

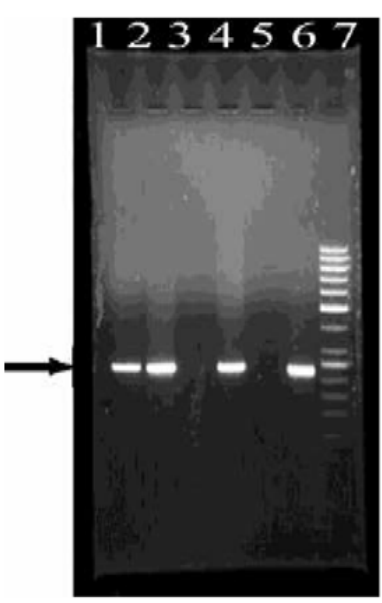

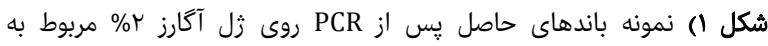

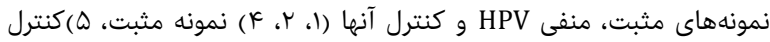

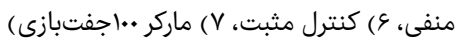

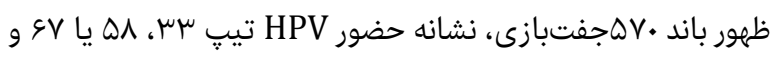

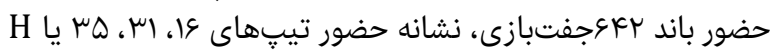

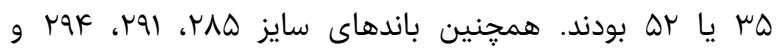

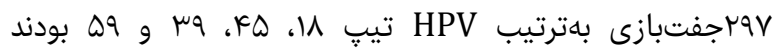

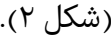

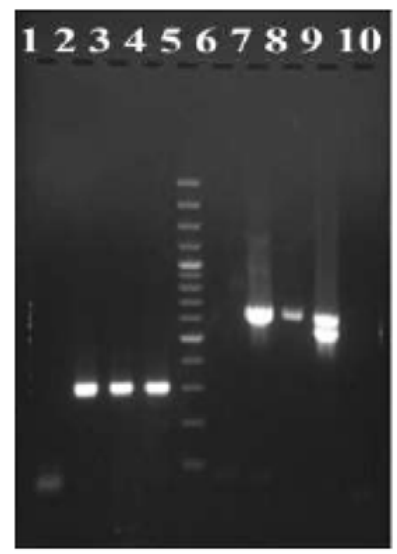

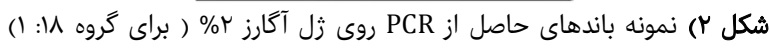

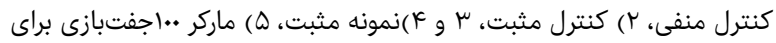

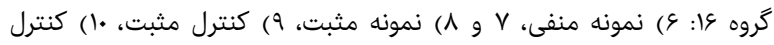

منفى)

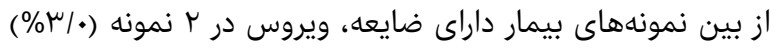
با وجود علايم بالينى ضايعه درونايىتليالى و اثرائ درات تغييرن 
تشكر و قدردانى: از همكاران آزمايشكاه جنرال بيمارستان صارم

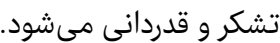
تاييديه اخلاقى: موردى از سوى نويسند مئدان ذكر نشده است.

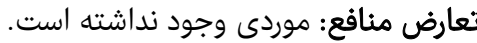

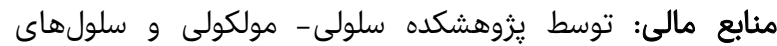
بنيادى تامين شده است.

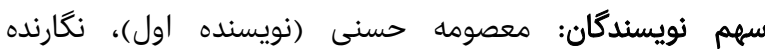

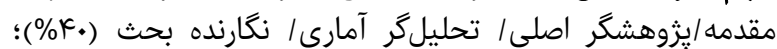

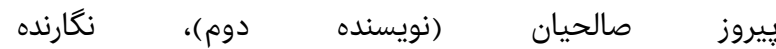

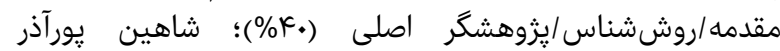

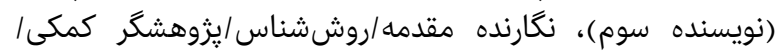

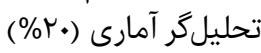

منابع

1- Karimi N. Treatment of Condyloma acuminatum with krayotherapy [Dissertation]. Kermanshah: Kermanshah Medical Science University; 1995.

2- Malloy C, Sherris J, Herdman C. HPV DNA testing: Technical and programmatic issues for cervical cancer prevention in low-resource settings [Internet]. Semantic Scholar: 2015 [updated 2000 Dec 1; cited 2001 Dec 2]. Avilable from: https://goo.gl/7VKtgJ.

3- Definitions \& Characteristics of HPV: Merck Medicos Modules; 2006.

4- James WD, Berger T, Dirk M. Andrews' Diseases of the Skin. 9th edition. Philadelphia: Saunders; 2000.

5- Czegledy J, Gergely L, Hernadi Z, Poka R. Detection of human papillomavirus deoxyribonucleic acid in the female genital tract. Med Microbiol Immunol. 1989;178(6):309-14.

6- Nasiri S, Ghalamkarpoor F, Saberi A, Parvaneh V. Study of human papilloma virus in anogenital condylomas by PCR method. Iran J Clin Infect Dis. 2008;3(1):19-23.

7- Park JS, Namkoong SE, Lee JM, Kim EJ, Chee YH, Han GT, et al. Cervical intraepithelial neoplasia 3, coinfected with HPV-16 and -18 -case report. J Korean Med Sci. 1993;8(2):162-5.

8- Garland SM, Tabrizi S. Methods for HPV detection: Polymerase chain reaction assays. In: Monsonego J, editor. Emerging issues on HPV infections: From science to practice. Switzerland: Karger; 2006. pp. 63-72.

9- Sterling JC, Kurtz JB. Viral infections. In: Champion RH, Burton JL, Burns DA, Breathnach SM. Textbook of Dermatology. $8^{\text {th }}$ Edition. London: Blackwell Science; 1998. pp. 995-1095.

10- Solomon D, Schiffman M, Tarone R, ALTS Study group. Comparison of three management strategies for patients with atypical squamous cells of undetermined significance: Baseline results from a randomized trial. J Natl Cancer Inst. 2001;93(4):293-9.

11- Cope JU, Hildesheim A, Schiffman MH, Manos MM, Lörincz AT, Burk RD, et al. Comparison of the hybrid capture tube test and PCR for detection of human papillomavirus DNA in cervical specimens. J Clin Microbiol. 1997;35(9):2262-5.

12- Nomelini RS, Barcelos AC, Michelin MA, Adad SJ, Murta EF. Utilization of human papillomavirus testing for cervical cancer prevention in a university hospital. Cad Saude Publica. 2007;23(6):1309-18.
و در اكثر موارد عامل اصلى در آلودگى مخاط مخاط رحم و نواحى

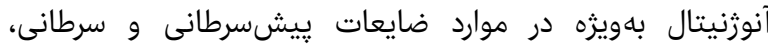

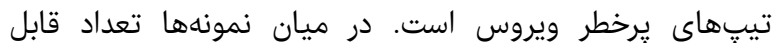

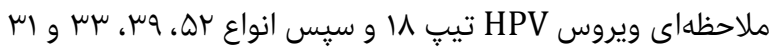

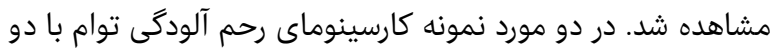

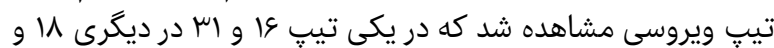

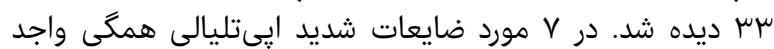

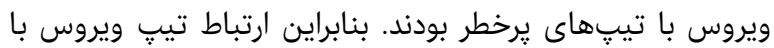

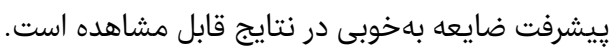

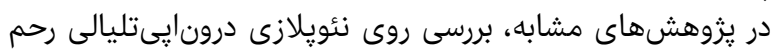

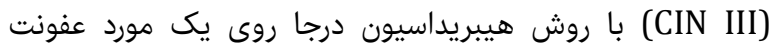

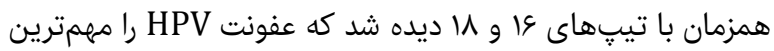

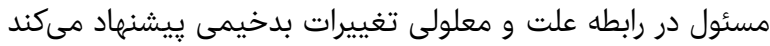

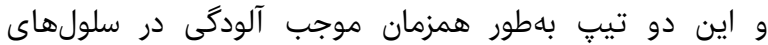

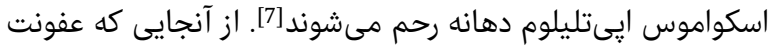

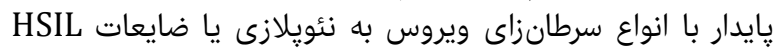

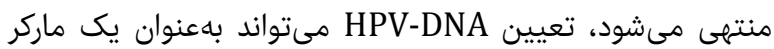

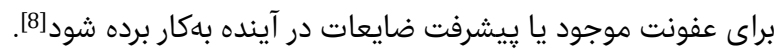

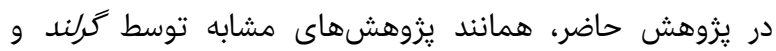

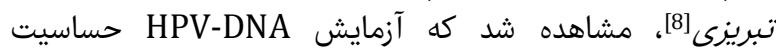

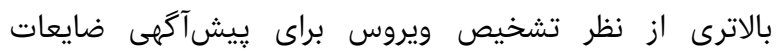
ييشسرطانى (LSIL, HSIL) نسبت بـانه سيتولوزى دارد.

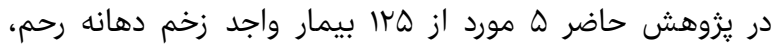

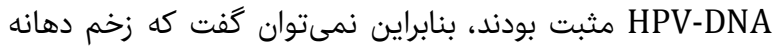

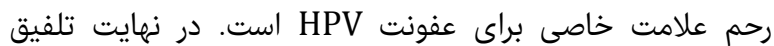

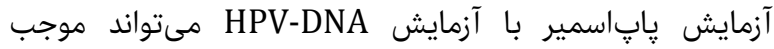

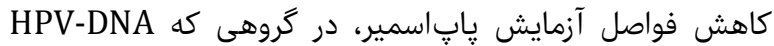

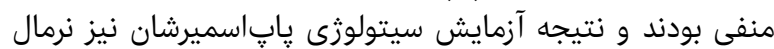

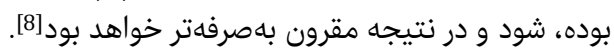

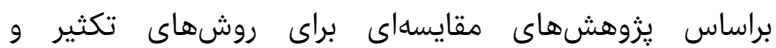

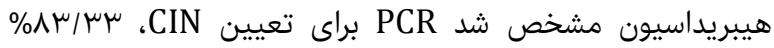

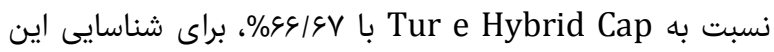

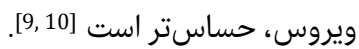
در يك آناليز حساسيت براى تعيين ضايعات شديد، مشخص شد شد

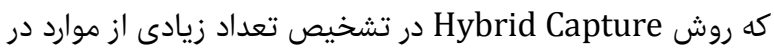

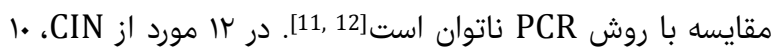

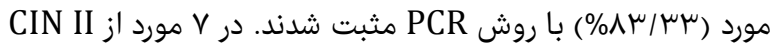
و CINIII همخى با اين روش مثبت شوش شدند.

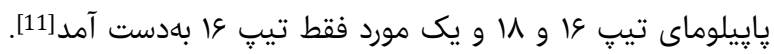

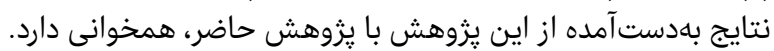

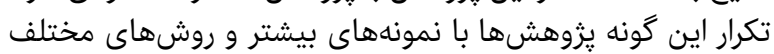

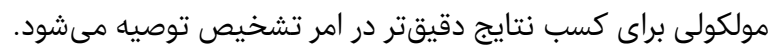

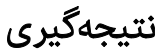

\% 9V علايم درونايىتليالى در سيتولوزى دهانه رحم با وجود

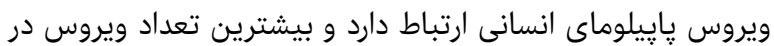

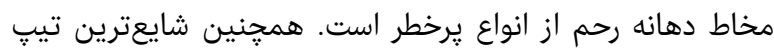

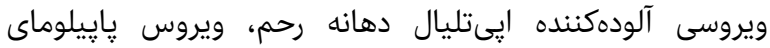
انسانى نوع عاست است. 